\title{
A Matched-Pair Study Comparing Surgery Plus Neoadjuvant Radio-Chemotherapy and Surgery Alone for High Rectal Cancers
}

\author{
DIRK RADES ${ }^{1}$, RASMUS PEULICHE VOGELSANG ${ }^{2}$, MAXI TREDER ${ }^{1}$, STEFAN JANSSEN $^{1,3}$, \\ STEVEN E. SCHILD ${ }^{4}$, NIELS HENRIK HOLLÄNDER ${ }^{5}$ and ISMAIL GÖGENUR ${ }^{2}$ \\ ${ }^{1}$ Department of Radiation Oncology, University of Lübeck, Lübeck, Germany; \\ ${ }^{2}$ Department of Surgery, Zealand University Hospital, Kфge, Denmark; \\ ${ }^{3}$ Medical Practice of Radiotherapy and Radiation Oncology, Hannover, Germany; \\ ${ }^{4}$ Department of Radiation Oncology, Mayo Clinic, Scottsdale, AZ, U.S.A.; \\ ${ }^{5}$ Department of Oncology and Palliative Units, Zealand University Hospital, Naestved, Denmark
}

\begin{abstract}
Background/Aim: The value of neoadjuvant radiochemotherapy for high rectal cancers is controversial. This study compared surgery plus neoadjuvant radiochemotherapy to surgery alone. Patients and Methods: Fifty-two patients with stage II/III high rectal cancers treated with surgery plus neoadjuvant radiochemotherapy were matched (1:4) to 208 patients treated with surgery alone. Matching criteria included age ( $\leq 65$ vs. $>65$ years), gender and UICC-stage (II vs. III). These criteria were identical in all five patients used for each 1:4 matching. Both groups were compared for overall survival $(O S)$. Results: On univariate analyses, age $\leq 65$ years $(p<0.001)$ was significantly associated with improved OS. A trend towards improved OS was found for neoadjuvant radiochemotherapy $(p=0.078)$ and UICC-stage II $(p=0.060)$. On multivariate analysis, age $(p<0.001)$ remained significant, and neoadjuvant radiochemotherapy showed a trend towards better OS $(p=0.073)$. Conclusion: Given the limitations of this study, the results showed that neoadjuvant radiochemotherapy may improve OS in patients with stage II/III high rectal cancers. However, these results need to be verified in a prospective randomized trial.
\end{abstract}

For patients with rectal cancers of the lower third $(\leq 5.0 \mathrm{~cm}$ from the anal verge according to the European Society for Medical Oncology ESMO) and the middle third (5.1-10.0 cm),

Correspondence to: Professor Dirk Rades, MD, Department of Radiation Oncology, University of Lübeck, Ratzeburger Allee 160, 23562 Lübeck, Germany. Tel: +49 45150045401, Fax: +49 45150045404, e-mail: rades.dirk@gmx.net

Key Words: High rectal cancers, neoadjuvant radiochemotherapy, surgery alone, comparative study, overall survival. treatment should include neoadjuvant radiotherapy or radiochemotherapy followed by surgery and adjuvant chemotherapy (1). However, the treatment recommendations for high rectal cancers (upper third, 10.1-15.0 cm) are less clear. Controversy exists whether high rectal cancers are more appropiately treated as colon cancers (surgery followed by chemotherapy) or as true rectal cancers including neoadjuvant radiotherapy or radiochemotherapy. Current guidelines are difficult to follow and require interpretation. For example, the recommendation of the ESMO guidelines state that a tumor located $>12 \mathrm{~cm}$ from the anal verge (above the peritoneal reflection) should be treated as a colon cancer, which was not supported by other studies (1). Furthermore, the choice of $>12 \mathrm{~cm}$ as cut-off did not match with the ESMO definition of high rectal cancers (i.e. $10.1-15 \mathrm{~cm}$ from the anal verge). Moreover, the results from randomized trials are conflicting. According to a trial from Sweden and the 5-year results of a Dutch trial, neoadjuvant radiotherapy or radiochemotherapy did not significantly improve the outcomes of patients with high rectal cancers $(2,3)$. In contrast, an additional analysis of a trial from Germany and the MRC CR07/NCIC-CTG C016 trial found that the addition of neoadjuvant radiotherapy or radiochemotherapy improved patient outcomes $(4,5)$. When considering the conflicting results from the available trials, it becomes clear that further research focusing particularly on high rectal cancers is warranted. The present study compared surgery preceded by neoadjuvant radiochemotherapy to surgery alone in patients with locally advanced high rectal cancers.

\section{Patients and Methods}

Fifty-two patients with stage II/III high rectal cancer (10.1 to $15.0 \mathrm{~cm}$ from the anal verge on endoscopy based on the ESMO guidelines (1)) treated with surgery preceded by neoadjuvant radiochemotherapy 
between 2008 and 2017 (group A) were matched (1:4) to 208 patients treated with surgery without neoadjuvant radio-chemotherapy (group B). Thus, the total number of patients included in this study was $\mathrm{N}=260$. The matching criteria included age at surgery $(\leq 65 \mathrm{vs} .>65$ years), gender and tumor stage according to the Union for International Cancer Control (UICC) (stage II vs. III) (Table I). The three criteria had to be identical in all five patients used for each 1:4 matching.

In the radio-chemotherapy group, radiotherapy was administered with $1.8 \mathrm{~Gy}$ fractions five times per week up to a total of $50.4 \mathrm{~Gy}$. One patient refused the last fraction and received a total dose of 48.6 Gy. Irradiated volumes included the primary tumor and the regional lymph nodes. The concurrent chemotherapy consisted mainly of two cycles of 5-flourouracil or capecitabine, which were supplemented by oxaliplatin in three patients. In both treatment groups, surgery was generally performed as total mesorectal excision. Following surgery, up to 6 additional courses of chemotherapy were administered.

Both treatment groups were compared for OS, which like in the Dutch rectal cancer trial $(3,6)$, was referenced from the date of surgery, applying the Kaplan-Meier method (7). In addition, age, gender and UICC-stage were investigated for potential associations with OS. Differences between the Kaplan-Meier curves were calculated using the Wilcoxon test (univariate analyses). Those factors that were significant $(p<0.05)$ or showed a trend $(p<0.10)$ on univariate analyses were additionally evaluated for independence in a multivariate manner with the Cox regression model.

\section{Results}

In the entire cohort, the OS rates at 1, 2, 3, 4 and 5-years were $92 \%, 84 \%, 76 \%, 69 \%$ and $65 \%$, respectively. On univariate analyses, age $\leq 65$ years $(p<0.001)$ was significantly associated with improved OS. In addition, a trend was found for the addition of neoadjuvant radiochemotherapy ( $p=0.078$, Figure 1) and UICC-stage II $(p=0.060)$. Detailed results of the univariate analysis of OS are shown in Table II. On multivariate analysis, age (risk ratio $(\mathrm{RR})=2.56,95 \%$ confidence interval $(\mathrm{CI})=1.63-4.10$, $p<0.001)$ maintained significance, and neoadjuvant radiochemotherapy showed a trend towards improved OS $(\mathrm{RR}=1.86,95 \% \mathrm{CI}=0.95-4.22, p=0.073)$. The UICC-stage was not significant on multivariate analysis $(\mathrm{RR}=1.53$, $95 \% \mathrm{CI}=0.89-2.84, p=0.13)$.

\section{Discussion}

Rectal cancer is a very common tumor with an annual incidence of 15-25 new cases per 100,000 inhabitants in the European Union, which is expected to further increase in the future (1). Therefore, considerable efforts have been undertaken to discover new more active systemic agents, radiochemotherapy protocols and surgical techniques, in order to improve the outcomes for these patients (8-12). One important question that has not been answered clearly is whether patients with high rectal cancers benefit more from neoadjuvant radiotherapy or radio-chemotherapy like patients with rectal cancers of the lower and middle third. No randomized trial is available that was particularly focused on this subgroup of rectal cancer patients. Recommendations are currently based on subgroup analyses of existing trials. However, these data did not indicate the best treatment. One important trial was published in 2005, which compared surgery preceded by short-course radiotherapy with $5 \times 5$ Gy to surgery alone in 908 patients with rectal cancer (2). In the entire cohort, 243 patients had high rectal cancer, which was defined as located $\geq 11 \mathrm{~cm}$ from the anal verge. In this subgroup, the local recurrence rates were $8 \%$ with and $12 \%$ without neoadjuvant radiotherapy $(p=0.3)$. Similar results were obtained from a Dutch trial of 1,748 eligible patients, of whom 533 patients had high rectal cancer located 10.1$15-0 \mathrm{~cm}$ from the anal verge, that also compared surgery plus neoadjuvant radiotherapy with $5 \times 5$ Gy to surgery alone (3, 6 ). At 2 years, the local recurrence rates in patients with high rectal cancer were $3.8 \%$ without and $1.3 \%$ with neoadjuvant radiotherapy $(p=0.17)(6)$. At 5 years, the local recurrence rates were $6.2 \%$ and $3.7 \%$, respectively $(p=0.12)(3)$. In contrast to these trials, the addition of neoadjuvant radiotherapy or radiochemotherapy led to better outcomes in subgroup analyses of two other trials $(4,5)$. In the MRC CR07 trial, 207 of 1,350 patients had high rectal cancer (10.1-15.0 cm from the anal verge) (4). Patients received either neoadjuvant radiotherapy with $5 \times 5$ Gy followed by surgery or surgery alone. In the minority of patients with an involvement of the circumferential resection margin, surgery was supplemented by adjuvant radiochemotherapy (45 Gy in 1.8-Gy fractions plus concurrent 5-FU). Three-year local recurrence rates were $1.2 \%$ in patients with and $6.2 \%$ in patients without neoadjuvant radiotherapy (hazard $\operatorname{ratio}(\mathrm{HR})=0.16 ; 95 \%$ confidence interval $(\mathrm{CI})=0.07-0.47$, $p<0.05)(4)$. In an update analysis of a randomized trial from Germany (13), 5-year local recurrence rates were $2.5 \%$ in patients with high rectal cancers $(10.0-16.0 \mathrm{~cm}$ from anal verge) receiving preoperative radiochemotherapy $(\mathrm{N}=83)$ compared to $10.4 \%$ in those patients with high rectal cancers $(\mathrm{N}=45)$ who did not receive preoperative or postoperative radiochemotherapy (5).

Since the results from these prospective trials are conflicting, additional comparative studies, particularly focusing on the treatment of high rectal cancers, are needed. Therefore, the present study compared surgery with and without neoadjuvant radiochemotherapy in patients with locally advanced high rectal cancer. To our knowledge, this is the first study particularly focusing on patients with high rectal cancers. Our previous study including almost the same radiochemotherapy cohort as this study demonstrated that the regimen used for neoadjuvant radiochemotherapy was well tolerated (14). Grade 3 acute toxicities were observed in $19 \%$ of patients, and were less common than in the neoadjuvant treatment group of the German trial (27\% grade 3 or 4 toxicities) $(13,14)$. Late 
Table I. Distribution of the factors used for the matching between the two treatment groups.

\begin{tabular}{lcc}
\hline Factor & $\begin{array}{c}\text { Neoadjuvant } \\
\text { radiochemotherapy } \\
+ \text { surgery } \\
\text { N patients }(\%)\end{array}$ & $\begin{array}{c}\text { Surgery alone } \\
\text { N patients (\%) }\end{array}$ \\
\hline Age at surgery & & \\
$<65$ Years $(\mathrm{N}=120)$ & $24(46)$ & $96(46)$ \\
$>65$ Years $(\mathrm{N}=140)$ & $28(54)$ & $112(54)$ \\
Gender & $25(48)$ & $100(48)$ \\
Female $(\mathrm{N}=125)$ & $27(52)$ & $108(52)$ \\
Male $(\mathrm{N}=135)$ & $12(23)$ & $48(23)$ \\
UICC-stage & $40(77)$ & $160(77)$ \\
Stage II $(\mathrm{N}=60)$ & & \\
Stage III $(\mathrm{N}=200)$ &
\end{tabular}

UICC: Union for International Cancer Control.

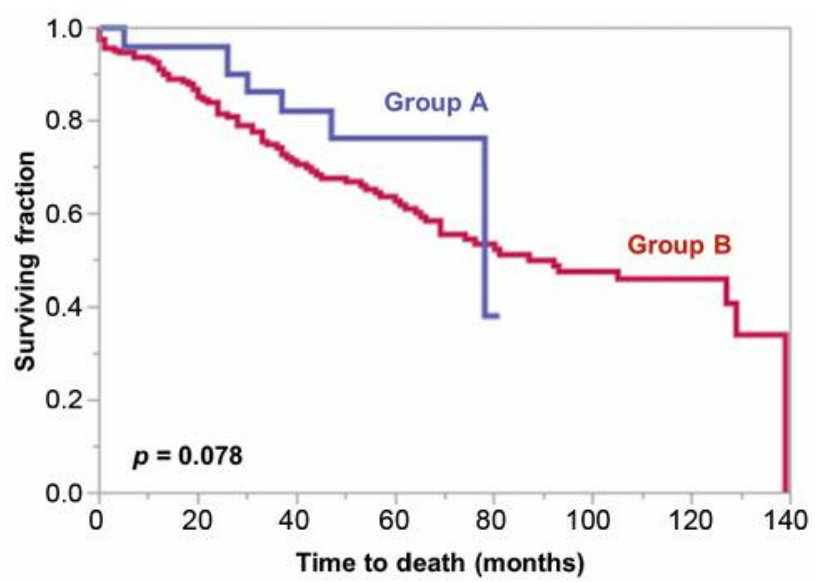

Figure 1. Kaplan-Meier curves of group A (patients with neoadjuvant radiochemotherapy) and group $B$ (patients without neoadjuvant radiochemotherapy). The p-Value was obtained from the Wilcoxon test.

Table II. Univariate analysis of overall survival (OS) with survival rates up to 5 years. The p-Values were obtained from the Wilcoxon test.

\begin{tabular}{|c|c|c|c|c|c|c|}
\hline Factor & $\begin{array}{c}\text { OS at } \\
1 \text { Year }(\%)\end{array}$ & $\begin{array}{c}\text { OS at } \\
2 \text { Years }(\%)\end{array}$ & $\begin{array}{c}\text { OS at } \\
3 \text { Years }(\%)\end{array}$ & $\begin{array}{c}\text { OS at } \\
4 \text { Years }(\%)\end{array}$ & $\begin{array}{c}\text { OS at } \\
5 \text { Years }(\%)\end{array}$ & $p$-Value \\
\hline \multicolumn{7}{|l|}{ Age at surgery } \\
\hline$<65$ Years $(\mathrm{N}=120)$ & 96 & 92 & 86 & 81 & 77 & \\
\hline$>65$ Years $(\mathrm{N}=140)$ & 89 & 78 & 68 & 59 & 53 & $<0.001$ \\
\hline \multicolumn{7}{|l|}{ Gender } \\
\hline Female $(\mathrm{N}=125)$ & 97 & 87 & 80 & 75 & 67 & \\
\hline Male $(\mathrm{N}=135)$ & 88 & 82 & 73 & 65 & 63 & 0.10 \\
\hline \multicolumn{7}{|l|}{ UICC-stage } \\
\hline Stage II $(\mathrm{N}=60)$ & 95 & 91 & 91 & 82 & 72 & \\
\hline Stage III $(\mathrm{N}=200)$ & 91 & 82 & 72 & 66 & 63 & 0.060 \\
\hline \multicolumn{7}{|c|}{ Neoadjuvant radiochemotherapy } \\
\hline Yes $(\mathrm{N}=52)$ & 96 & 96 & 86 & 76 & 76 & \\
\hline No $(\mathrm{N}=208)$ & 91 & 82 & 74 & 68 & 63 & 0.078 \\
\hline Entire cohort $(\mathrm{N}=260)$ & 92 & 84 & 76 & 69 & 65 & \\
\hline
\end{tabular}

OS: Overall survival; UICC: Union for International Cancer Control. Bold indicates significant $p$-Values.

toxicities were mild or moderate. Forty-three percent of the patients experienced at least one surgery-related complication, but all complications were managed (14).

In the present study, 52 patients receiving a neoadjuvant radiochemotherapy regimen were matched and compared to 208 patients who received no neoadjuvant treatment. In both univariate and multivariate analyses, addition of radiochemotherapy showed a trend towards better OS. Thus, neoadjuvant radiochemotherapy may provide a benefit for patients with high rectal cancers and not only for those patients with tumors of the lower and middle third. When interpreting these results, the limitations of the present study need to be considered including its retrospective design, which bears the risk of hidden selection biases, and the fact that the patients were matched for only three criteria. However, results of a properly designed, prospective randomized trial will likely not be available soon. Hopefully, the present study will pave the way for such a trial.

In summary, given the limitations of this study, neoadjuvant radiochemotherapy showed a trend for improved OS in patients with stage II/III high rectal cancers. However, the results need to be verified in a prospective randomized trial. The findings of the present study suggest that the role of neoadjuvant radiochemotherapy, which currently is not the standard treatment for high rectal cancers, may be underestimated. This study will hopefully encourage physicians treating rectal cancer 
patients to initiate a randomized trial comparing surgery preceded by radiochemotherapy to surgery alone in patients with high rectal cancers.

\section{Conflicts of Interest}

On behalf of all Authors, the corresponding Author states that there is no conflict of interest related to this study.

\section{Acknowledgements}

The study is part of the project InnoCan, which is funded by Interreg Deutschland-Danmark with funds from the European Regional Development Fund.

\section{References}

1 Glynne-Jones R, Wyrwicz L, Tiret E, Brown G, Rödel C, Cervantes A and Arnold D; ESMO Guidelines Committee: Rectal cancer: ESMO Clinical Practice Guidelines for diagnosis, treatment and follow-up. Ann Oncol 28: iv22-iv40, 2017.

2 Folkesson J, Birgisson H, Pahlman L, Cedermark B, Glimelius B and Gunnarsson U: Swedish Rectal Cancer Trial: long lasting benefits from radiotherapy on survival and local recurrence rate. J Clin Oncol 23: 5644-5650, 2005.

3 Peeters KC, Marijnen CA, Nagtegaal ID, Kranenbarg EK, Putter H, Wiggers T, Rutten H, Pahlman L, Glimelius B, Leer JW and van de Velde CJ; Dutch Colorectal Cancer Group: The TME trial after a median follow-up of 6 years: increased local control but no survival benefit in irradiated patients with resectable rectal carcinoma. Ann Surg 246: 693-701, 2007.

4 Sebag-Montefiore D, Stephens RJ, Steele R, Monson J, Grieve R, Khanna S, Quirke P, Couture J, de Metz C, Myint AS, Bessell E, Griffiths G, Thompson LC and Parmar M: Preoperative radiotherapy versus selective postoperative chemoradiotherapy in patients with rectal cancer (MRC CR07 and NCIC-CTG C016): a multicentre, randomised trial. Lancet 373: 811-820, 2009.

5 Sauer R, Liersch T, Merkel S, Fietkau R, Hohenberger W, Hess C, Becker H, Raab HR, Villanueva MT, Witzigmann H, Wittekind C, Beissbarth T and Rödel C: Preoperative versus postoperative chemoradiotherapy for locally advanced rectal cancer: results of the German CAO/ARO/AIO-94 randomized phase III trial after a median follow-up of 11 years. J Clin Oncol 30: 1926-1933, 2012.

6 Kapiteijn E, Marijnen CA, Nagtegaal ID, Putter H, Steup WH, Wiggers T, Rutten HJ, Pahlman L, Glimelius B, van Krieken JH, Leer JW and van de Velde CJ; Dutch Colorectal Cancer Group: Preoperative radiotherapy combined with total mesorectal excision for resectable rectal cancer. N Engl J Med 345: 638646, 2001
7 Kaplan EL and Meier P: Non parametric estimation from incomplete observations. J Am Stat Assoc 53: 457-481, 1958.

8 Yamamoto S, Kanai T, Osumi K, Yo K, Takano K, Tsutsui M, Nakanishi R, Yoshikawa Y, Kaneko Y and Nakagawa M: Anastomotic leakage using linear stapling device with preattached bioabsorbable polyglycolic acid felt after laparoscopic anterior resection. Anticancer Res 37: 7083-7086, 2017.

9 Nonaka T, Fukuda A, Maekawa K, Nagayoshi S, Tokunaga T, Takatsuki M, Kitajima T, Taniguchi K and Fujioka H: Clinical and oncological outcomes of laparoscopic lateral pelvic lymph node dissection in advanced lower rectal cancer: Singleinstitution experience. Anticancer Res 37: 5095-5100, 2017.

10 Eisterer W, Piringer G, DE Vries A, Öfner D, Greil R, Tschmelitsch J, Samonigg H, Sölkner L, Gnant M and Thaler J; Austrian Breast and Colorectal Cancer Study Group: Neoadjuvant chemotherapy with capecitabine, oxaliplatin and bevacizumab followed by concomitant chemoradiation and surgical resection in locally advanced rectal cancer with high risk of recurrence - a phase II study. Anticancer Res 37: 2683-2691, 2017.

11 Rödel C, Graeven U, Fietkau R, Hohenberger W, Hothorn T, Arnold D, Hofheinz RD, Ghadimi M, Wolff HA, LangWelzenbach M, Raab HR, Wittekind C, Ströbel P, Staib L, Wilhelm M, Grabenbauer GG, Hoffmanns H, Lindemann F, Schlenska-Lange A, Folprecht G, Sauer R and Liersch T; German Rectal Cancer Study Group: Oxaliplatin added to fluorouracilbased preoperative chemoradiotherapy and postoperative chemotherapy of locally advanced rectal cancer (the German CAO/ARO/AIO-04 study): final results of the multicentre, openlabel, randomised, phase 3 trial. Lancet Oncol 16: 979-989, 2015.

12 Ide S, Toiyama Y, Okugawa Y, Oki S, Yasuda H, Fujikawa H, Yoshiyama S, Hiro J, Kobayashi M, Ohi M, Araki T and Kusunoki M: Clinical significance of C-reactive protein-to-albumin ratio with rectal cancer patient undergoing chemoradiotherapy followed by surgery. Anticancer Res 37: 5797-5804, 2017.

13 Sauer R, Becker H, Hohenberger W, Rödel C, Wittekind C, Fietkau R, Martus P, Tschmelitsch J, Hager E, Hess CF, Karstens JH, Liersch T, Schmidberger H and Raab R; German Rectal Cancer Study Group: Preoperative versus postoperative chemoradiotherapy for rectal cancer. N Engl J Med 351: 1731-1740, 2004.

14 Treder M, Janssen S, Holländer NH, Schild SE and Rades D: Role of neoadjuvant radio-chemotherapy for the treatment of high rectal cancer. Anticancer Res 38: 5371-5377, 2018. 